\title{
PROTEOLYSIS OF SARS-ASSOCIATED CORONAVIRUS SPIKE GLYCOPROTEIN
}

\author{
Graham Simmons, Andrew J. Rennekamp and Paul Bates*
}

\section{INTRODUCTION}

Severe acute respiratory syndrome-associated coronavirus (SARS-CoV) mediates attachment, receptor engagement and entry via its spike glycoprotein (S). S-dependent viral entry requires the presence of a primary receptor, angiotensin converting enzyme-2 (ACE2), ${ }^{1}$ while the C-type lectins, DC-SIGN, DC-SIGNR, and LSECtin act as attachment factors, promoting binding to a subset of target cells. ${ }^{2-5}$

SARS-CoV S, like other coronavirus spike glycoproteins, contains two leucine/ isoleucine heptad repeats (HR1 and HR2) located in the C-terminal third of the glycoprotein. ${ }^{6-8}$ By homology to other fusion proteins, such as influenza hemagglutinin (HA) and HIV gp160, HR1 and HR2 are thought to drive membrane fusion through their interaction together. HR1 and HR2 from each member of the trimeric spike pack together to form a highly stable structure known as the six-helix bundle. The events following receptor engagement and leading up to six-helix bundle formation are less defined.

Viral entry mediated by SARS-CoV S is exquisitely sensitive to compounds able to raise the $\mathrm{pH}$ of cellular endosomes. ${ }^{2,9,10}$ Thus, a $\mathrm{pH}$-dependent component appears to be required for cell-free viral infection mediated by S. However, S-dependent cell-to-cell fusion can occur at neutral $\mathrm{pH},{ }^{1}$ and furthermore fusion is not enhanced by acidic $\mathrm{pH} .{ }^{9}$ Therefore, it appears unlikely that $\mathrm{S}$ has a direct requirement for acidic conditions in order to undergo the conformational rearrangements required for six-helix bundle formation, as is seen for other $\mathrm{pH}-$ dependent fusion proteins such as HA. In contrast, when cells expressing endogenous, low levels of ACE2 were used as targets for cellto-cell fusion, treatment of the $\mathrm{S}$ glycoprotein expressing effectors with trypsin is necessary in order for efficient fusion to be observed. ${ }^{9}$ Thus, we hypothesize that in order for efficient cell-free virus infection to occur, similar proteolytic activity is required, and that trypsin mimics the activity of a $\mathrm{pH}$-dependent cellular protease, hence explaining the sensitivity to compounds able to raise endosomal $\mathrm{pH}$.

* A.J. Rennekamp and P. Bates, University of Pennsylvania School of Medicine, Philadelphia, Pennsylvania 19104. G. Simmons, Blood Sytems Research Institute, San Francisco, CA 94118. 


\section{TRYPSIN - MEDIATED PROTEOLYSIS OF S PROTEIN}

The precise requirement and role of glycoprotein processing for coronavirus entry and membrane fusion is not well defined. Many coronaviruses, such as mouse hepatitis virus (MHV), contain a furin cleavage site within S that yields S1 and S2 subunits. ${ }^{10,11}$ This site, however, is not absolutely required for infection, although lack of cleavage lowers Smediated cell-cell fusion. ${ }^{11}$ In contrast, SARS-CoV S, both when overexpressed in cells, and on mature virions, is predominantly in a full-length, unprocessed form (Fig. 1A, lefthand lane). However, cell-to-cell fusion mediated by SARS-CoV S was enhanced by pretreatment of effector cells with trypsin. ${ }^{9}$ Thus, the role of proteolysis of SARS-CoV S by trypsin-like proteases in cell-free virus infection was examined.

\subsection{Trypsin Treatment of Cell-Free Virions}

Lentiviral-based pseudovirions incorporating SARS-CoV S into their lipid coats ${ }^{9}$ were produced in 293T cells [virions termed HIV(SARS-CoV S)]. Analysis revealed that following pretreatment with trypsin, a C-terminal fragment of approximately $100 \mathrm{kDa}$ is detectable using polyclonal sera raised against the C-terminal extracellular portion of $\mathrm{S}$ (Fig. 1A, middle lane). A fragment of this size would be expected following processing at the predicted S1/S2 boundary. ${ }^{1}$ However, rather than enhancing titers as might be predicted from processing of other viral fusion proteins such as influenza HA, ${ }^{12}$ pretreatment of HIV(SARS-CoV S) with trypsin led to a $95 \%$ reduction in infectivity (Fig. 1B). Mutagenesis suggested that trypsin-mediated cleavage of $S$ did indeed occur at basic residues around the predicted S1/S2 boundary, although alteration of these sites did not dramatically alter infectivity titers (data not shown).

\subsection{Trypsin-Mediated Enhancement of Infection by Cell-Bound Virions}

We hypothesize that trypsin proteolysis can mimic the action of an endosomal protease. Thus, it is likely that ACE2 engagement at the cell surface occurs prior to proteolysis in the endosome. Therefore, the trypsin activation was attempted following attachment of virus to the cell surface, rather than in solution.

As previously demonstrated, ${ }^{2,9,10}$ pretreatment of cells with agents able to raise the $\mathrm{pH}$ of endosomes, such as ammonium chloride, dramatically reduces infection mediated by SARS-CoV S (Fig. 1C). However, if HIV(SARS-CoV S) particles are first bound to the cell surface at $4^{\circ} \mathrm{C}$, then trypsin activated, infection occurred even in the presence of ammonium chloride (Fig. 1C). Similar results were obtained using live, replication competent SARS-CoV virus infection of Vero E6 cells. ${ }^{13}$ Thus, trypsin treatment of S not only enhances its ability to mediate membrane fusion, but also relieves it of a requirement for acid $\mathrm{pH}$ during the viral entry process.

$\mathrm{S}$ lacking basic residues at the S1/S2 boundary ( $\arg 667$ and lys672, both mutated to ala) is no longer processed by trypsin to give a 100 - $\mathrm{kDa} \mathrm{C}$-terminal fragment (data not shown). However, these mutants can still be activated by trypsin cleavage at the cell surface to overcome the block to infection mediated by ammonium chloride (data not shown). Thus, it is unlikely that the proteolytic processing mediated by trypsin that leads to activation of infectivity occurs at the $\mathrm{S} 1 / \mathrm{S} 2$ boundary, but rather at a distinct site. 
A.

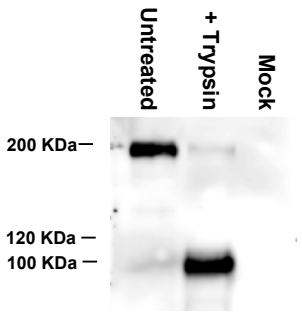

B.

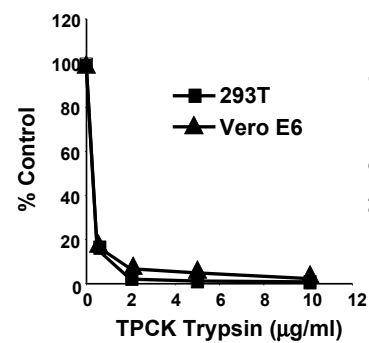

C.

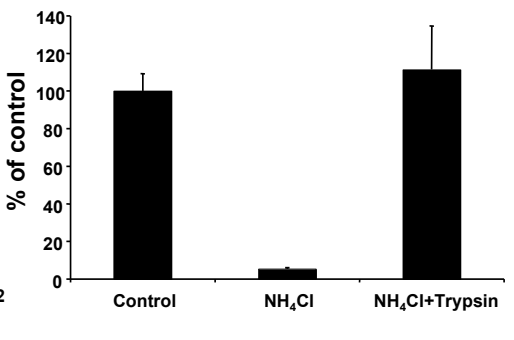

Figure 1. Effect of trypsin on SARS-CoV S. (A) Ultracentrifuge concentrated HIV(SARS-CoV S) pseudovirions were incubated with TPCK-trypsin $(10 \mu \mathrm{g} / \mathrm{ml})$ for 15 minutes at $25^{\circ} \mathrm{C}$ and analyzed by SDSPAGE. (B) HIV(SARS-CoV S) encoding luciferase was incubated with trypsin, and used to challenge $293 \mathrm{~T}$ or VeroE6 cells. After 48 hours, cells were analyzed for luciferase activity. Results are presented as a percentage of no trypsin control. (C) Vero E6 cells, pretreated with PBS (Control) or $20 \mathrm{mM}$ ammonium chloride $\left(\mathrm{NH}_{4} \mathrm{Cl}\right)$, were incubated with $\mathrm{HIV}(\mathrm{SARS}-\mathrm{CoV} \mathrm{S})$ at $4^{\circ} \mathrm{C}$ to allow binding, but not entry. Cells were incubated with serum-free medium at $37^{\circ} \mathrm{C}$ for 10 minutes and treated with trypsin $\left(\mathrm{NH}_{4} \mathrm{Cl}+\mathrm{Trypsin}\right)$. Cells were assayed as in (B). Results are presented as a percentage of no $\mathrm{NH}_{4} \mathrm{Cl}$, no trypsin control.

\section{EFFECTS OF PROTEASE INHIBITORS ON SARS-COV ENTRY}

The ability of trypsin treatment to overcome ammonium chloride inhibition of Smediated infection suggests that lysosomotropic agents may prevent proteolysis of S by $\mathrm{pH}$-dependent, endosomal proteases. Thus, the effects of various protease inhibitors on HIV(SARS-CoV S), as well as live SARS-CoV, infection were examined in detail.

Leupeptin is an inhibitor of both serine and cysteine proteases, while aprotinin and E64c specifically inhibit serine and cysteine proteases, respectively. Pepstatin is an aspartate protease inhibitor. Entry of HIV pseudovirions mediated by SARS-CoV S was efficiently blocked by both leupeptin and E64c, with $\mathrm{IC}_{95}$ 's of 15.2 and $8.2 \mu \mathrm{M}$, respectively (Table 1). Infection mediated by VSV-G, a pH-dependent viral membrane fusion protein was not inhibited by either leupeptin nor E64c (Table 1). Likewise, pretreatment of target cells with either pepstatin or aprotinin had no effect on infection mediated by either of the tested envelopes (Table 1).

Infection of $293 \mathrm{~T}$ cells transiently expressing ACE2 by replication-competent SARS-CoV was also inhibited by leupeptin. ${ }^{13}$ Similarly to the ammonium chloride results (Fig. 1C), trypsin treatment of virions bound at the cell surface overcame the block to infection mediated by pretreatment with leupeptin. ${ }^{13}$

The specificity of endosomal cysteine proteases in mediating SARS-CoV infection was further examined using more specific inhibitors of cysteine proteases. Z-leu-leu-leufluoromethyl ketone (Z-11l-FMK), an inhibitor of both cathepsin B and L efficiently inhibited infection of HIV(SARS-CoV S), but not HIV(VSV-G). In contrast, CA-074, a selective inhibitor of cathepsin B, did not dramatically affect infection of either pseudovirus (Table 1). These results suggest that cathepsin L, but not cathepsin B, plays a critical role in SARS-CoV S-mediated entry. 
Table 1. Inhibition of S-mediated entry by protease inhibitors.

\begin{tabular}{llcc}
\hline Inhibitor & Target proteases & \multicolumn{2}{c}{$\mathrm{IC}_{95}(\mu \mathrm{M})$} \\
\cline { 3 - 4 } & & HIV(SARS-CoV S) & HIV(VSV-G) \\
\hline Leupeptin & Serine, cysteine & 15.2 & $>200$ \\
Pepstatin & Aspartate & $>200$ & $>200$ \\
E64c & Cysteine & 8.2 & $>200$ \\
Aprotinin & Serine & $>200$ & $>200$ \\
Z-111-FMK & Cathepsin B and L & 3.5 & $>200$ \\
CA-074 & Cathepsin B & $>200$ & $>200$ \\
\hline${ }^{a}$ Z-111-FMK, Z-leu-leu-leu-fluoromethyl ketone & &
\end{tabular}

A panel of relatively specific inhibitors of cathepsin $\mathrm{L}$ activity, Z-Phe- $\mathrm{Phe}-\mathrm{CH}_{2} \mathrm{~F}, \mathrm{Z}$ Phe-Tyr-CHO, Z-Phe-Tyr-(t-Bu)-CHN 2 , and 1-naphthalenesulfonyl-Ile-Trp-CHO, were used to determine the role of cathepsin $\mathrm{L}$ in viral entry. Indeed, all four compounds potently inhibited HIV(SARS-CoV S) pseudotype infection (Fig. 2). In contrast, these inhibitors were found to have no effect on HIV(VSV-G) entry. ${ }^{13}$ An inhibitor of cathepsin K (Boc-Phe-Leu-NHNH-CO-NHNH-Leu-Z) was significantly less effective at inhibiting SARS-CoV S-mediated entry, although at high concentrations some inhibition was noted (Fig. 2A). Whether this is due to cross inhibition of cathepsin L at high inhibitor concentrations, or suggestive of cathepsin $\mathrm{K}$ playing a minor role in $\mathrm{S}$ activation, is unclear.

\section{IN VITRO PROTEOLYSIS OF S PROTEIN}

In order to directly address the role of cathepsin L, a novel intervirion fusion assay was established in order to allow the study of S-mediated membrane fusion in a cell-free environment. Lentiviral pseudovirions can be prepared incorporating either SARS-CoV $\mathrm{S}$, or its receptor, ACE2. ${ }^{13}$ The two sets of particles are then mixed in the presence or absence of proteases in order to study the requirements for activation of S glycoprotein's membrane fusion potential. In order to quantify intervirion fusion, the ACE2 bearing virions package luciferase as a reporter gene, while the SARS-CoV S enveloped particles lack a reporter gene, but co-incorporate the envelope glycoprotein from subgroup A avian sarcoma and leukosis virus (ASLV-A env). Following mixing of the two viral populations, the particles are plated on HeLa cells that lack ACE2, but stably express the ASLV-A receptor, Tva. Thus, ASLV-A env will mediate infection of these cells by the dual ASLV-A/SARS-CoV S particles. Only if S has mediated intervirion fusion with ACE2 expressing particles will the cells be transduced by the luciferase reporter gene encoded by the ACE2 particles. Hence, luciferase activity acts as a direct measure of intervirion fusion. In addition, in order to prevent uptake of mixed virions into endosomes and subsequent activation of $\mathrm{S}$ by endogenous proteases, the target cells were pretreated with leupeptin. As a consequence, mixing of the two populations of virions led to no resultant luciferase activity in the HeLa cells (Fig. 2B). In contrast, if, after mixing the two populations of virions, samples were treated with either trypsin or recombinant cathepsin L, efficient transduction of target cells by the luciferase reporter gene was observed (Fig.2B). As predicted from the lack of inhibition by specific cathepsin B 
inhibitors, recombinant cathepsin B showed no enhancement of intervirion fusion (Fig. 2B).

Enhancement of intervirion fusion by cathepsin $\mathrm{L}$ was found to be $\mathrm{pH}$-dependent, with the highest levels of fusion seen at a $\mathrm{pH}$ of 5 , or below. ${ }^{13}$ In contrast, little, or no intervirion fusion was observed with cathepsin $\mathrm{L}$ at neutral $\mathrm{pH} .{ }^{13}$ Conversely, trypsin most efficiently gave intervirion fusion at neutral $\mathrm{pH}$ (data not shown), arguing against $\mathrm{pH}$ having a direct effect on $\mathrm{S}$. Thus, the apparent requirement for cathepsin L activity for efficient S-mediated entry explains the sensitivity to compounds such as ammonium chloride that raise endosomal $\mathrm{pH}$.

Due to the requirement for binding to receptor-positive cells before treatment by trypsin (Fig. 1), we hypothesized that receptor interactions may be required prior to proteolysis. Indeed, in the intervirion assay, following mixing of HIV(SARS-CoV S/ASLV-A env) with HIV-luc(ACE2) virions, an incubation step at elevated temperatures was required in order for proteolysis to enhance fusion. ${ }^{13}$ If virions were incubated at $4^{\circ} \mathrm{C}$ prior to trypsin treatment, no intervirion fusion was observed. ${ }^{13}$ These results suggest that conformational changes induced by binding to ACE2 may indeed be required prior to proteolysis.

\section{DISCUSSION}

Overall, these experiments suggest a new paradigm for viral entry into target cells. Namely, that for SARS-CoV S, receptor-mediated conformational changes induce exposure of a cryptic cleavage site within the viral envelope glycoprotein. Cleavage at this site by $\mathrm{pH}$-dependent cellular proteases is then necessary in order to fully activate the $\mathrm{S}$ protein's membrane fusion potential. Further characterization of this phenomena is likely to highlight steps in the activation of $\mathrm{S}$ that may yield targets for specific inhibitors of entry. Indeed, the finding that cathepsin L is an important activating protease for SARS infection suggests cellular proteases as a target for therapeutic intervention. The entry process described here for SARS-CoV S protein also raises the question whether

A.

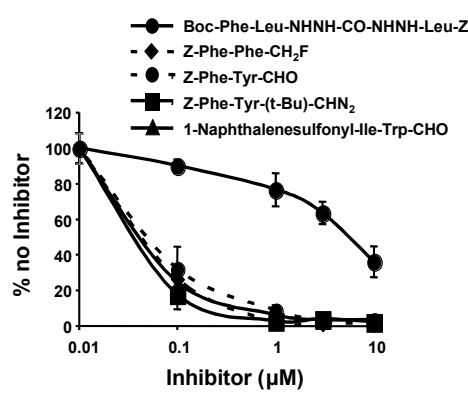

B.

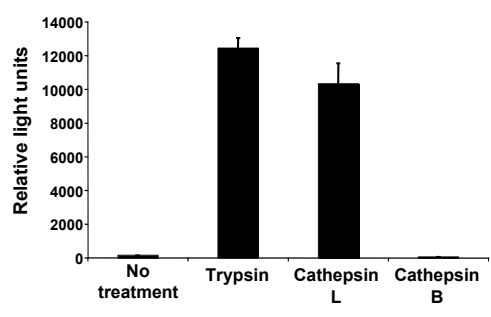

Figure 2. Role of cathepsin L. (A) Inhibition of HIV(SARS-CoV S) pseudovirions by cathepsin inhibitors. (B) Activation of intervirion fusion by protease treatment. HIV-luc(ACE2) and HIV(SARS-CoV S/ASLV-A env) particles were mixed, pre-incubated at $37^{\circ} \mathrm{C}$ and then treated with PBS, trypsin $(10 \mu \mathrm{g} / \mathrm{ml})$, or cathepsin L or B $(2 \mu \mathrm{g} / \mathrm{ml})$ for 10 minutes at $25^{\circ} \mathrm{C}$. Proteases were inactivated by leupeptin $(20 \mu \mathrm{g} / \mathrm{ml})$, incubated at $37^{\circ} \mathrm{C}$ for 30 minutes to allow membrane fusion and plated on $\mathrm{HeLa} / \mathrm{Tv}$ a cells pretreated with leupeptin $(20 \mu \mathrm{g} / \mathrm{ml})$. 
other classically defined pH-dependent viruses display this dependence due to a requirement for acidic protease activation and not $\mathrm{pH}$-induced structural rearrangements as is commonly assumed.

This work was by the NIH Mid Atlantic Regional Center for Biodefense and Emerging Infectious Diseases Grant U54 AI057168 and NIH grants R01 AI43455, R21 AI059172, and R21 AI058701.

\section{REFERENCES}

1. W. Li, M. J. Moore, N. Vasilieva, J. Sui, S. K. Wong, M. A. Berne, M. Somasundaran, J. L. Sullivan, K. Luzuriaga, T. C. Greenough, H. Choe, and M. Farzan, Angiotensin-converting enzyme 2 is a functional receptor for the SARS coronavirus, Nature 426, 450-454 (2003).

2. Z. Y. Yang, Y. Huang, L. Ganesh, K. Leung, W. P. Kong, O. Schwartz, K. Subbarao, and G. J. Nabel, pHDependent entry of SARS-CoV is mediated by the spike glycoprotein and enhanced by dendritic cell transfer through DC-SIGN, J. Virol. 78, 5642-5650 (2004).

3. A. Marzi, T. Gramberg, G. Simmons, P. Moller, A. Rennekamp, M. Krumbiegel, M. Geier, J. Eisemann, N. Turza, B. Saunier, A. Steinkasserer, S. Becker, P. Bates, H. Hofmann, and S. Pohlmann, DC-SIGN and DCSIGNR interact with Marburg virus and the S protein of SARS-CoV, J. Virol. 78, 12090-12095 (2004).

4. S. Jeffers, S. Tusell, L. Gillim-Ross, E. Hemmila, J. Achenbach, G. Babcock, W. Thomas, Jr., L. Thackray, M. Young, R. Mason, D. Ambrosino, D. Wentworth, J. Demartini, and K. Holmes, CD209L (L-SIGN) is a receptor for SARS-CoV, Proc. Natl. Acad. Sci. USA 101, 15748-15753 (2004).

5. T. Gramberg, H. Hofmann, P. Moller, P. F. Lalor, A. Marzi, M. Geier, M. Krumbiegel, T. Winkler, F. Kirchhoff, D. H. Adams, S. Becker, J. Munch, and S. Pohlmann, LSECtin interacts with filovirus glycoproteins and the spike protein of SARS coronavirus, Virology 340, 224-236 (2005).

6. B. J. Bosch, B. E. Martina, R. Van Der Zee, J. Lepault, B. J. Haijema, C. Versluis, A. J. Heck, R. De Groot A. D. Osterhaus, and P. J. Rottier, Severe acute respiratory syndrome coronavirus infection inhibition using spike protein heptad repeat-derived peptides, Proc. Natl. Acad. Sci. USA 101, 8455-8460 (2004).

7. S. Liu, G. Xiao, Y. Chen, Y. He, J. Niu, C. R. Escalante, H. Xiong, J. Farmar, A. K. Debnath, P. Tien, and S. Jiang, Interaction between heptad repeat 1 and 2 regions in spike protein of SARS-CoV: implications for virus fusogenic mechanism and identification of fusion inhibitors, Lancet 363, 938-947 (2004).

8. B. Tripet, M. W. Howard, M. Jobling, R. K. Holmes, K. V. Holmes, and R. S. Hodges, Structural characterization of the SARS-coronavirus spike S fusion protein core, J. Biol. Chem. 279, 20836-20849 (2004).

9. G. Simmons, J. D. Reeves, A. J. Rennekamp, S. M. Amberg, A. J. Piefer, and P. Bates, Characterization of SARS-CoV spike glycoprotein-mediated viral entry, Proc. Natl. Acad. Sci. USA 101, 4240-4245 (2004).

10. M. Frana, J. Behnke, L. Sturman, and K. Holmes, Proteolytic cleavage of the E2 glycoprotein of murine coronavirus: host-dependent differences in proteolytic cleavage and cell fusion, J. Virol. 56, 912-920 (1985).

11. C. De Haan, K. Stadler, G. Godeke, B. Bosch, and P. Rottier, Cleavage inhibition of the murine coronavirus spike protein by a furin-like enzyme affects cell-cell but not virus-cell fusion, J. Virol. 78, 6048-6054 (2004).

12. H. D. Klenk, R. Rott, M. Orlich, and J. Blodorn, Activation of influenza A viruses by trypsin treatment, Virology 68, 426-439 (1975).

13. G. Simmons, D. N. Gosalia, A. J. Rennekamp, J. D. Reeves, S. L. Diamond, and P. Bates, Inhibitors of cathepsin L prevent severe acute respiratory syndrome coronavirus entry, Proc. Natl. Acad. Sci. USA 102, 11876-11881 (2005). 